Wichtig Information / Important Information!

Wenn Sie diesen Aufsatz zitieren, dann nehmen Sie bitte auf die Druckfassung Bezug! When citing this article, please refer to the print-version:

Andreas Trampota: Virtue, Perception and Reality. Virtue Ethics between Cultural Sensitivity and Relativism. In: Idris Nassery, Jochen Schmidt (Hg.), Moralische Vortrefflichkeit in der pluralen Gesellschaft. Tugendethik aus philosophischer, christlicher und muslimischer Perspektive, Paderborn: Schöningh 2016, S. 133-150.

\title{
Virtue, Perception and Reality. Virtue ethics between cultural sensitivity and relativism
}

\section{Andreas Trampota}

This essay reflects upon moral virtue - moral excellence - in a pluralistic society from a philosophical perspective. Since virtue concepts play a major role in the field of ethics, this is an issue of great importance. Asking the question of their significance from an intercultural perspective immediately raises the further question of their objectivity and obligatory nature. The normative character of many virtue concepts seems to be deeply rooted in specific forms of life with their respective traditions and cultures. However, if they are embedded in a particular form of life with its specific idea of human flourishing there would be no obligation to cultivate them outside of it. There may be a form of intersubjective justification for such concepts. But if their normativity is rooted in the form of life of specific communities with their tradition and culture, it seems to be restricted specific communities with their local forms of rationality. Hence, we need to ask: Are the virtues just a reflection of particular value systems, one among many. Or is there a foundation for at least some virtues which secures them a form of objectivity of unrestricted, universal scope ${ }^{1}$

\section{In the normative order virtue takes second place}

Let me put my cards on the table right at the start. In my view, virtue ethics is not - as some philosophers suggest - an independent approach in the field of normative ethics like utilitarianism and deontology. ${ }^{2}$ The reason I emphasize this right away is that it is essential for what I will be saying in what follows. From an Aristotelian perspective - which in mattes of

\footnotetext{
${ }^{1}$ Mein Aufsatz: Werte und Normen ...

${ }^{2}$ See, e.g., Rosalind Hursthouse, On Virtue Ethics, Oxford: Oxford University Press 1999. She begins her article on virtue ethics in the Stanford Encyclopedia by saying: "Virtue ethics is currently one of three major approaches in normative ethics." (Hursthouse, Rosalind, "Virtue Ethics", in: The Stanford Encyclopedia of Philosophy (Fall 2013 Edition), Edward N. Zalta (ed.), URL = <http://plato.stanford.edu/archives/fall2013/entries/ethics-virtue/>.)
} 
virtue I find very convincing in many respects - the concept of virtue is a secondary concept ${ }^{3}$ It is not a primary concept since in normative ethical reasoning it is dependent on other concepts. It presupposes the concepts of the right ethical decision and - closely connected with it - that of the right action. Virtue - at least in the Aristotelian sense (which has had great historical influence) - is that constitution of the appetitive faculty (of the desiderative faculty) which makes human beings capable of making right decisions resulting in right acting. In other words: For judging people's character or character dispositions as good or as bad (as virtuous or as lacking in virtue) we first need to know how their decisions and resulting actions are to be judged. Hence, in terms of normative ethical thinking the rightness of someone's action is prior to the goodness of his or her character. The quality of someone's character cannot be judged without having an idea of what counts as a right decision and a right action. In a modification of a well-known quotation from the New Testament one might express this by saying: By their fruits - by their decisions and actions - you will recognize the

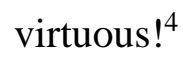

Certainly, having a good character, thereby being a virtuous person, means a great deal more than continuously taking good decisions and doing the right thing, since this is something which a merely self-controlled person might be able to do, at least to a certain extent . In a nutshell, virtue is the ideal of a radical unity and consistency of the human person in her pursuit of the good in all its various forms..$^{5}$ Needless to say, this is an ideal of which we constantly fall short. Still, despite this fact that virtue concerns the quality of the character of a person and, hence, goes far beyond good decision-making and the corresponding actions, there is no other criterion for a good character than right choice and right acting. I agree with Aristotle when he states that virtue is a habitual disposition of character which is directed at making choices (a hexis prohairetike). If it is genuine, it necessarily results in good choices. ${ }^{6}$ And there is no other measure for the quality of the character dispositions than the decisions and actions to which they lead.

\section{Virtues ensure that ethical values are deeply rooted in reality}

Having said this I hasten to add: From virtue taking second place in the normative order it by no means follows that virtues are insignificant. On the contrary, ethical theories which do not

\footnotetext{
${ }^{3}$ Not all interpreters of Aristotle agree with me on this. My interpretation owns much to: Ricken ... Christoph Halbig's new book (Der Begriff der Tugend ...) in this respect has similar intuitions.

${ }^{4}$ Cf. Matthew 7:16.

${ }^{5}$ Tugend: ein Ideal der Einheit. Ricken sagt: “Tugend ist das Ideal der radikalen Widerspruchsfreiheit und Einheit der menschlichen Person". ... in: Ethik und Sozialwissenschaft ...

${ }^{6}$ Vgl. NE II-6 $1106 \mathrm{~b} 36$.
} 
attach great importance to the formation of the character (which is one of the major concerns of virtue ethics) are in my opinion rationalistic in a pejorative sense. What ensures that ethical values are deeply rooted in reality are the virtues and the moral education and self-education by which they are acquired. Without the virtue-ethical concern for character-building many of the moral values which are constantly invoked in public life remain - at least, to the extent that they are not enforced by law - rather ineffective.

Nussbaum begins her essay on non-relative virtues ${ }^{7}$ with the observation that the virtues are attracting increasing interest in contemporary philosophical debate and she explains this with a widespread dissatisfaction with ethical theories which are remote from concrete human experience. Although I disagree with her claim that this is due to the influence of the utilitarian and Kantian concern with universal principles of broad generality ${ }^{8}$, I agree with her assumption that (a) this remoteness from human experience is a defect in an approach to ethical questions and that (b) the concept of virtue might play a prominent role in an alternative approach.

In what follows I begin by sketching something like the ideal of the virtuous person, which I will then critically examine. And this will lead to some conclusions about the role of moral excellence in a pluralistic society.

\section{The ideal of a virtuous person spelled out in epistemic, perceptional terms}

The ideal picture of the virtuous person which I am going to draw builds on the conviction that virtue is something that shapes our perception and experience of reality and thereby motivates us to act. ${ }^{9}$ The major ethical imperative in this virtue ethical approach is: Learn to see better! As a matter of fact, this is what King Lear (in the play of the same name by Shakespeare) is told when, because of a misunderstanding, he tragically abandons his daughter Cordelia. He is told by a friend: "See better, Lear" and "Learn to see better, Lear"! 10 This is a virtue-ethical imperative since in this account virtuous character dispositions are supposed to make us capable to perceive things which might otherwise remain invisible to us.

\footnotetext{
${ }^{7}$ Martha Nussbaum, "Non-relative Virtues: An Aristotelian Approach”, in: Russ Shafer-Landau (ed.), Ethical Theory, chap. 67, pp. 684-700 (first published in: Midwest Studies in Philosophy, vol. 13.1, September 1988, pp. 32-53).

${ }^{8}$ In my view, it is a misunderstanding that universal principles are "universals principles of broad generality, in which particular contexts, histories, and persons do not occur" (ibid., p. 684, italics mine.) ... universality ... generality ...

${ }^{9}$ It is inspired by Iris Murdoch's Platonic account of morality ... using epistemic notions ...

${ }^{10}$ Cf. Shakespeare, King Lear, Act 1, Scene 1, p. 7.
} 


\section{The perception of the virtuous participates in the active, creative potential of the human imagination}

The perception in the ethical context, of course, is not perception in the literal sense. It is $a$ specific form of moral perception which is closely connected with our linguistic capabilities and the faculty of judgment. Hence, we are not talking about perception understood as a passive faculty for the reception of sense data. Perception in the moral sense participates in the active and creative potential of the faculty of imagination which is closely interwoven with our linguistic ability. A purely passive perception cannot have a moral quality since there is no responsibility for passive impressions. By participating in the active and creative potential of the human imagination, however, our perception turns into a moral faculty.

Iris Murdoch is one of the philosophers who thought a great deal about this fusion of perception and imagination, especially as regards its importance in the field of ethics. At its core it is a fusion of two functions of the mind: the picturing and realizing of what is real with the ordering activity. The following passage from Metaphysics as a Guide to Morals spells out the connection:

"The work of imagination in art may be seen as a symbol of its operation elsewhere; this might also be expressed by saying that there is artistry in the sorting, separating and connecting movement of the mind in other areas, in science and scholarship, and in morals and politics where an ordering activity is fused with an ability to picture what is quite other; especially of course to picture and realise, make real to oneself, the existence and being of other people. Imagination in politics: to imagine the consequences of policies, to picture what it is like for people to be in certain situations (unemployed, persecuted, very poor), to relate axiomatic moral ideas (for instance about rights) to pragmatic and utilitarian considerations. The concept of imagination is, on reflection, an essential one, not least perhaps because it can strengthen or clarify the sense in which 'we are all artists'."11

Reality is made normative, one could say, by the constructive work of the imagination in conjunction with the patient and humble exercise of attention. Moral development is initiated by the application of our creative imagination and the use of our linguistic potential in

\footnotetext{
${ }^{11}$ Iris Murdoch, Metaphysic as a Guide to Morals, p. 321f., italics mine.
} 
restoring and redefining our concepts. Imagination, unlike fantasy, ${ }^{12}$ is not used to escape the world, but to unite it, to make it one and to discover value in it. ${ }^{13}$

\section{Moral perception and moral vocabulary}

Since perception merges with imagination, moral perception and moral vocabulary are closely tied to each other. Hilary Putnam said about the vocabulary which shapes our moral perception in an interview:

"The more subtle and the more astute our moral vocabulary is, the better we are able to take well considered decisions. (...) I wouldn't say that principles are irrelevant in morality. But a major problem in this area is the application of the principles." 14

Philosophers from Kant to John McDowell have pointed out that experience is conceptualized and the concepts we use can mislead as well as lead, conceal as well as reveal. ${ }^{15}$ And this becomes particularly clear in the ethical field. Any application of moral principles (e. g. virtue concepts) is preceded by a perception of what we think is real and the moral vocabulary we use to this end. It is precisely for this reason that Iris Murdoch requested: "We can only move properly in a world that we can see, and what must be sought for is vision."16 As moral agents we can only act in the world that we are able to perceive. Hence, the first thing which is needed, even before we start thinking about moral principles, is a vision! We might think that we should just settle for what is rational about a specific situation in which we feel prompted to act. But when we do this, we have already, reflectively or unreflectively, imagined it in a certain way. ${ }^{17}$ For as moral agents we have to understand the world and thereby to construct this world. ${ }^{18}$ Hence, our perceptions constantly merge with our imaginations which are already evaluations:

\footnotetext{
${ }^{12}$ In an interview with Jeffrey Meyers Iris Murdoch said: "It is very difficult to attain, to create something which is not a fantasy. I'd want to make a distinction between fantasy and imagination, not the same as Coleridge's, but a distinction between the expression of immediate selfish feelings and the elimination of yourself in a work of art." (From a Tiny Corner in the House of Fiction: Conversations with Iris Murdoch Hardcover, Gillian Dooley (ed.), Columbia, SC 2012, p. 226, italics mine) by Gillian Dooley (Editor)p. 226

${ }^{13}$ Cf. Bagnoli, Carla, "Realism as a Moral Achievement", in: M. Ricciardi (ed.), The Philosophy of Iris Murdoch, in: 'Notizie di Politeia', 2002, pp. 51-63.

${ }^{14}$ Interview in the German newspaper, Die Welt' ... my translation ..

${ }^{15}$ Cf. Hilary Putnam, "The Depths and Shallows of Experience", in: M. D. Caro, D. MacArthur (eds.), Philosophy in an Age of Science, Cambridge/MA 2005 p. ???.

${ }^{16}$ Metaphysics, p. 303, italics mine.

${ }^{17}$ Cf. Metaphysics, p. 314f.

${ }^{18}$ Cf. Metaphysics, p. 385.
} 
"Our deepest imaginings which structure the world in which 'moral judgments' occur are already evaluations. Perception itself is a mode of evaluation. Any account of morality must at least set up a problem here. (...) We have to 'talk' and our talk will be largely 'imaginative' (we are all artists). How we see our situation is itself, already, a moral activity, and one which is, for better as well as worse, 'made' by linguistic process. (...) The point is, to put it picturesquely, that the 'transcendental barrier' is a huge wide various band (it resembles a transformer such as the lungs in being rather like a sponge) largely penetrable by the creative activity of individuals (though of course we are culturally marked 'children of our time' etc.) and this creativity is the place where the concept of imagination must be placed and defined."19

\section{In the epistemological order virtue and the perception which it makes possible are prior to moral principles}

The theory of virtue - we saw at the outset - is dependent on the concept of a right decision as regards its normativity. However, there is - as we just learned - also a dependence in another sense, relating not to the normative, but to the epistemological order. Moral principles which are meant to shape our decision-making process are dependent on what we are able to perceive of the "moral landscape" ${ }^{20}$, that is: the concrete, specific moral circumstances in which we are prompted to make a decision. The specific meaning which moral principles have with regard to concrete circumstances can only be grasped in the context of an inner 'moral landscape' which is established by the continuous truth-seeking activity of the human consciousness in its perception of the particular. People who lack a virtuous character won't be able to apply principles properly since they do not have the necessary discerning resources which allow them to see the relevant features of the given concrete circumstances.

What characterizes the virtuous person first and foremost is his grasp of the particular in the light of what his character makes him able to see and to discern. John McDowell has aptly described the interaction between virtuous character and perception in this process of discernment:

\footnotetext{
${ }^{19}$ Metaphysics, p. 314f.

${ }^{20}$ Iris Murdoch uses this term quite frequently ... Beleg für den ganzen Abschnitt
} 
"Occasion by occasion, one knows what to do, if one does, not by applying universal principles, but by being a certain kind of person: one who sees the situations in a certain distinctive way." 21

What one acquires by a moral upbringing which leads to virtuous character dispositions is not a code of rules - at any rate, not primarily -, but a perceptual capability:

"In moral upbringing what one learns is not to behave on conformity with rules of conduct, but to see situations in a special light, as constituting reasons for acting; this perceptual capacity, once acquired, can be exercised in complex novel circumstances, not necessarily capable of being foreseen and legislated for by a codifier of the conduct required by virtue, however wise and thoughtful he might be." 22

\section{Iris Murdoch's daughter-in-law example}

In her famous daughter-in-law example Iris Murdoch illustrated this interaction between the perceptual and conceptual resources of a virtuous person and actual perception itself. It tells the story of a mother-in-law who comes to an altogether different moral perception of her daughter-in-law. At first, she finds her quite a good-hearted girl, though certainly unpolished and lacking in dignity and refinement. Her daughter-in-law, so she thinks, is inclined to be pert and familiar, insufficiently ceremonious, brusque, sometimes positively rude, always tiresomely juvenile. ${ }^{23}$ But then she realizes by looking at her justly and lovingly, thereby overcoming her obscuring jealousy, that her daughter-in-law is not vulgar but refreshingly simple, not undignified but spontaneous, not noisy but cheerful, not tiresomely juvenile but delightfully youthful, and so on. And this change takes place in the inner world of the motherin-law. The outward behavior of her daughter-in-law has not changed in any way. ${ }^{24}$

\section{Virtue ethics and thick ethical concepts}

This is a good example for moral perception because it shows (1.) how much it depends on our linguistic resources and (2.) that it is mainly 'thick ethical concepts' (or 'secondary ethical concepts', as they are also referred to) which are relevant in this field of ethics. One of the essential differences between various approaches to ethics is that some operate with - what

\footnotetext{
${ }^{21}$ John McDowell, "Virtue and Reason", in: John McDowell, Mind, Value, and Reality, Cambridge/MA: Harvard University Press 1998, p. 73, italics mine.

${ }^{22}$ John McDowell, “Are Moral Requirements Hypothetical Imperatives?”, in: John McDowell, Mind, Value, and Reality, Cambridge/MA: Harvard University Press 1998, p. 85.

${ }^{23}$ Cf. Murdoch, Sovereignty of Good, 1970, p. 17.

${ }^{24}$ Cf. Murdoch 1970, p. 18.
} 
Bernard Williams in Ethics and the Limits of Philosophy called ${ }^{25}$ - 'thick ethical concepts' (concepts such as: courageous, inequitable, just, dishonest, chaste, unfaithful, cruel, rude, kind ...) and others operate with 'thin' ones (such as: right and wrong, good and bad, good and evil) which are abstract and formal. What is distinctive about the thick ethical concepts is that they undermine the strong division of facts and values since they have both a descriptive and an evaluative side. ${ }^{26}$ They play a prominent role in virtue ethics. And the conviction that they are preferable to thin ones has been an influential thesis ever since the relaunch of virtue ethics in contemporary moral thinking by Elisabeth Anscombe with her paper 'Modern Moral Philosophy' ${ }^{27}$

\section{Virtue concepts are rich in content, but deeply rooted in particular individuals or communities}

We have now reached a crucial point in our reflections. The so-called thick ethical concepts are much more specific - much richer in content - than thin ones; this is what bestows great significance upon them for ethical thinking. The flip-side of this richness in content, however, is that these concepts are deeply rooted in the mental life of an individual (think of the mother-in-law in Murdoch's example) or - from a political perspective - in the contingent social practices of a particular community. Hence, we have to say: The more specific ethical concepts are, the more rooted they are in the character of an individual and in the contingent social practices of a specific community, varying as their different 'life worlds' vary. ${ }^{28}$

\section{In pluralistic societies human beings are separated by different conceptions of what is good}

Should this rootedness of virtue-ethical concepts in particular individuals or communities be a cause for worry or alarm? Not as long as human beings live in traditional societies with a predominant role for custom and habit in which people share language, ethnicity, cultural values and a religious system. But today many people live in societies in which human beings "are separated by a variety of incompatible religious, philosophical and moral teachings" 29 . John Rawls rightly claimed that the major concern of political liberalism is how human beings who are separated in this way by different conceptions of what is good can live together. The

\footnotetext{
${ }^{25}$ Cf. Bernard Williams ...

${ }^{26}$ Putnam: The Collapse of the Fact/Value Dichotomy and Other Essays ...

27 'Modern Moral Philosophy' (1958)

${ }^{28}$ Cf. Putnam 2002, p. 112.

${ }^{29}$ Cf. Rawls 1993, p. xx.
} 
best starting point for ethical reflection in the intercultural field is the fact that is characteristic of most modern democratic societies, namely their recognition of a pluralism of different ideas of human flourishing, comprising different religious and moral values. ${ }^{30}$ This pluralism is taken for granted. And to the extent that it is "the work of free practical reason within the frame of free institutions" ${ }^{" 31}$ it is also cherished as something reasonable.

\section{Individuals should be able to change their life plans and their religious, moral and philosophical convictions without loss of their public identity}

There are different cultures with different traditions and different value systems which are an expression of different ideas of human flourishing. Liberal societies always have to take into account that people may change their life plans and their religious, moral and philosophical convictions for good reasons. This would certainly lead to a change of their personal identity; but it should not lead to a loss of their public identity. ${ }^{32}$

\section{Virtues as a reflection of particular cultures with their tradition}

What are the consequences of this for virtue ethics? Since many virtue-ethical approaches operate mainly with thick ethical concepts (the advantage of which I already mentioned), their potential to ground a way of ethical thinking which is helpful in the intercultural arena seems to be rather small precisely because of their deep roots in particular cultures and their traditions. Hence, it doesn't come as a surprise that Alasdair MacIntyre (whose books have played a major role in the renaissance of virtue ethics) thinks that virtues are always $a$ reflection of a particular culture. This becomes abundantly clear when he states:

"Homer, Sophocles, Aristotle, the New Testament and medieval thinkers differ from each other in too many ways. They offer us different and incompatible lists of the virtues; they give a different rank order of importance to different virtues; and they have different and incompatible theories of the virtues. If we were to consider later Western writers on the virtues, the list of divergences and incompatibilities would be enlarged still further; and if we extended our inquiry to Japanese, say, or American Indian cultures, the difference would become greater still. It would be all too easy to conclude that there were a number of rival and alternative conceptions of the virtues, but, even within the traditions which I have been delineating, no single core conception." 33

\footnotetext{
${ }^{30}$ John Rawls suggested this in 'Political Liberalism', p. xviii.

${ }^{31}$ Rawls 1993, p. 37.

${ }^{32}$ Cf. Ricken 1995 ...

${ }^{33}$ McIntyre 1984, p. 181 , italics mine.
} 
McIntyre - at least at this stage of his thinking - seems to believe that there is no universal standard of rationality which is independent of particular cultures and their traditions and, hence, no account of virtue which could claim to be universally binding.

\section{Does a virtue ethic lack the potential for rational criticism of local traditions?}

The main point of criticism of this kind of virtue-ethical approach is its lack of potential for rational criticism. Martha Nussbaum, amongst others, has pointed out the severe consequences of this stance in normative ethics as follows:

“... it is easy for those who are interested in supporting the rational criticisms of local traditions and in articulating an idea of ethical progress to feel that the ethics of virtue can give them little help. If the position of women, as established by local traditions in many parts of the world, is to be improved, if the traditions of slave holding and racial inequality, if religious intolerance, if aggressive and warlike conceptions of manliness, if unequal norms of material distribution are to be criticized in the name of practical reason, this criticizing (one might easily suppose) will have to be done from a Kantian or Utilitarian viewpoint, not through an Aristotelian approach." 34

\section{There is not one paradigm of human excellence, but many!}

Despite this serious criticism, what we can learn from MayIntyre is that, indeed, there are many possible paradigms of human excellence, most of which are not compatible. A virtue may be considered to be - as it is by Homer - a quality which enables an individual to discharge his or her specific social role; for Homer the paradigm of human excellence is the warrior. Alternatively, one could say that virtue is a quality which enables an individual to move toward the achievement of a specifically human end (telos), either natural or supernatural, as Aristotle, in the first case, and Aquinas and many religious writers, in the second, thought. Another way of looking at it would be to see virtue as a quality which has utility in achieving earthly and heavenly success, as for example Benjamin Franklin believed. Hence, there is - as MacIntyre rightly claims - not one paradigm of human excellence, but many; not one model of virtue, but many. ${ }^{35}$

\section{MacIntyre adheres to the basic tenets of virtue ethics although he is opposed to cultural relativism}

\footnotetext{
${ }^{34}$ Nussbaum 1988, p. 33, italics mine.

${ }^{35}$ Cf. McIntyre, After Virtue, p. 216.
} 
Because of such considerations many readers of MacIntyre's book After Virtue (first published in 1981) may have come to the conclusion that his virtue-ethical approach is a form of cultural relativism. For he seems to be saying that there are no standards for resolving ethical questions which do not have a reference to particular local traditions and practices. However, in his later book Whose Justice? Which Rationality? (first published in 1988) MacIntyre is very explicit about his opposition to cultural relativism and expresses himself in favor of some rational but also historically sensitive justification of virtue. ${ }^{36}$ I shall not express a view on his method of justification. What matters for the purpose of my reflections is that at all stages of his thinking he holds fast to the conviction - which is a fundamental feature of many virtue-ethical approaches - that virtue-ethical reasoning is closely and inseparably attached to a particular kind of community. One of the most illuminating passages in this regard can be found in MacIntyre's introduction to the Polish edition of After Virtue where he says:

\section{"The flourishing of the virtues requires and in turn sustains a certain kind of} community, necessarily a small-scale community, within which the goods of various practices are ordered, so that, as far as possible, regard for each finds its due place with the lives of each individual, or each household, and in the life of the community at large. Because, implicitly or explicitly, it is always by reference to some conception of the overall and final human good that other goods are ordered, the life of every individual, household or community by its orderings gives expression, wittingly or unwittingly, to some conception of the human good. And it is when goods are ordered in terms of an adequate conception of human good that the virtues genuinely flourish.

'Politics' is the Aristotelian name for the set of activities through which goods are ordered in the life of the community." 37

Only in the context of small-scale communities, MacIntyre thinks, virtues genuinely flourish and human beings have a chance to live lives they understand. ${ }^{38}$

\section{All human beings seek not the way of their ancestors, but the good.}

There is a lot to be said for this rootedness of certain forms of ethical reasoning in particular communities with their specific traditions and practices. Still, this by no means reflects the general thrust of Aristotle's virtue-ethical thinking which has proven to be highly influential

\footnotetext{
${ }^{36}$ Cf. Martha C. Nussbaum, "Recoiling from Reason”, in: New York Review of Books, December 7, 1989, Review of Whose Justice? Which Rationality? by Alasdair MacIntyre, University of Notre Dame Press.

${ }^{37}$ Quoted from: Stanley Hauerwas, ,The Virtues of Alasdair MacIntyre”, in: First Things 176 (October 2007), p. 35, italics mine.

${ }^{38}$ Cf. Stanley Hauerwas, see note 16.
} 
in the history of ethics. One of Aristotle's basic convictions is expressed in his Politics where he states: "(...) all human beings seek not the way of their ancestors, but the good." 39 By this he means that in every culture there is the human potential for transcending the values of one's own culture because of the universal human orientation towards the good. Hence, the whole idea of a culture which has only thick ethical concepts (concepts which are rooted in this particular culture) is - as Hilary Putnam rightly said - probably a myth. ${ }^{40}$

\section{Virtue ethics needs to be complemented by a form of reasoning which is shaped by discourse, intersubjective justification, universalism and objectivity.}

In my view, virtue ethics with its sensitivity to history, tradition and people's concrete moral experience (which makes virtue ethics so attractive!) can only be a serious option in the intercultural ethical field which is characteristic of many modern societies if it is complemented by a form of reasoning which is shaped by discourse, intersubjective justification, universalism and objectivity.

The experiential basis of at least some virtues is something that all human beings have in common.

Martha Nussbaum has shown that the idea of human flourishing as understood by Aristotle is able to make a valuable contribution to our attempt to offer ethical orientation in the intercultural field. The decisive factor in her interpretation of Aristotle's concept of virtue is the observation that Aristotle's list of virtues is intended to be universal in scope since it is based upon experiences that presumably all human beings have in common. ${ }^{41}$ The virtues are conceived as those dispositions of character that enable individuals to act appropriately in the respective sphere. ${ }^{42}$ Here is a list of the virtues with the spheres of shared human experiences to which they are related: ${ }^{43}$

\begin{tabular}{|l|l|}
\hline $\begin{array}{l}\text { Spheres of human experience - the } \\
\text { "grounding experiences": }\end{array}$ & The corresponding virtue: \\
\hline (1) Fear of important damages, especially death. & courage \\
\hline (2) Bodily appetites and their pleasures. & moderation \\
\hline
\end{tabular}

\footnotetext{
${ }^{39}$ Aristotle, Politics, $1268 \mathrm{a} 39 \mathrm{ff}$.

${ }^{40}$ Cf. Putnam 1994, p. 191.

${ }^{41}$ Cf. Martha Nussbaum, "Recoiling from Reason", in: The New York Review, Dec.

7 (1989): 36-41.

${ }^{42}$ Nussbaum, Non-relative virtues ..

${ }^{43}$ Nussbaum, Martha, "Non-relative Virtues: An Aristotelian Approach", in: Russ Shafer-Landau (ed.), Ethical Theory, chap. 67, pp. 684-700 (first published in: Midwest Studies in Philosophy, vol. 13.1, September 1988, p. 32-53).
} 


\begin{tabular}{|c|c|}
\hline (3) Distribution of limited resources & justice \\
\hline $\begin{array}{l}\text { (4) Management of one's personal property } \\
\text { where others are concerned. }\end{array}$ & generosity \\
\hline $\begin{array}{l}\text { (5) Management of personal property where } \\
\text { hospitality is concerned. }\end{array}$ & expansive hospitality \\
\hline $\begin{array}{l}\text { (6) Attitudes and actions with respect to one's } \\
\text { own worth. }\end{array}$ & greatness of soul \\
\hline (7) Attitude to slights and damages. & mildness of temper \\
\hline $\begin{array}{l}\text { (8) "Association and living together and the } \\
\text { fellowship of words and actions" ... }\end{array}$ & \\
\hline (8a) Truthfulness in speech: & truthfulness \\
\hline (8b) Social association of a playful kind: & $\begin{array}{l}\text { easy grace (contrasted with coarseness, } \\
\text { rudeness, insensitivity) }\end{array}$ \\
\hline (8c) Social association more generally: & $\begin{array}{l}\text { a nameless virtue, but a kind of } \\
\text { friendliness (contrasted with irritability } \\
\text { and grumpiness) }\end{array}$ \\
\hline (9) Attitude to the good and ill fortune of others & $\begin{array}{l}\text { proper judgment (contrasted with } \\
\text { enviousness, spitefulness, etc.) }\end{array}$ \\
\hline (10) Intellectual life & $\begin{array}{l}\text { the various intellectual virtues (such as } \\
\text { perceptiveness, knowledge, etc.) }\end{array}$ \\
\hline (11) The planning of one's life and conduct & practical wisdom \\
\hline
\end{tabular}

In this model every virtue is related to a universal form of human experience. It is, for example, the virtue of courage which enables individuals to function properly in circumstances where they have to face - and deal with the fear of - extreme personal harm, especially death. Hence, when people argue about what is conducive to human flourishing they argue about the same kind of experiences, advancing competing specifications of the same virtue. There is a 'grounding experience' which they all have in common and there is a form of objectivity since we can criticize "local and traditional moralities in the name of a more inclusive account of the circumstances of human life, and of the needs for human functioning that those circumstances call forth..." ${ }^{44}$. 
Nicolai Hartmann, one of the eminent German philosophers in the first half of the $20^{\text {th }}$ century, noticed in his reflections on the dimensions of value in Aristotle's Nicomachean Ethics that ethical values need to match the real structures of human life, by which he meant human necessities, needs and tasks. He calls this aspect of the moral value its ontological determination in contrast to its axiological determination. It is firmly rooted in the real world and precedes the use of freedom by human beings. Looked at in this way one could well say that ethical values are relative. However, they are not relative in relation to the valuing subject, but relative in relation to prevailing types of situations of human acting (the ontological aspect of human values). They are what Aristotle calls the 'peri ti' - the phenomenological basis or framework - of the ethical values. ${ }^{45}$ This is what Nussbaum with regard to the virtues in experiential terms calls the 'grounding experiences' ${ }^{46}$.

\section{The priority of the right over the $\operatorname{good}^{47}$}

Let me draw some conclusions from what I have been saying. If moral virtue is supposed to have an objective validation, as I think it should, then (1) we need to consider the grounding experience that fixes the point of reference of the respective virtue and (2) we need to reflect on what we think counts as the appropriate choice in this sphere of experience. If virtue ethics doesn't want to lose its deep rootedness in history, tradition and human practices there is probably no other foundation for a critical examination of virtue-ethical convictions than our shared human experience!

As I said at the outset of my reflections we also need criteria for what counts as the right decision and the right action. The empirical basis of the virtues which is open to intercultural studies and comparisons is not enough to establish the criteria. The empirical approach allows us to criticize local and traditional moralities in the name of a more inclusive account of the human good. ${ }^{48}$ This is a good starting point for approaching conflicts in the intercultural field. But it is not sufficient for settling major moral disagreements in this field.

\footnotetext{
${ }^{45}$ Vgl. Hartmann 1957, S. 200, 207, 212. Nicolai Hartmann, Die Wertdimensionen der Nikomachischen Ethik, S. 213.

46 Beleg?

${ }^{47}$ Cf. Rawls ...

${ }^{48}$ Nussbaum writes in Non-relative Virtues: An Aristotelian Approach on p. 690: “... a sketch for an objective human morality based upon the idea of virtuous action - that is, of appropriate functioning in each human sphere. The Aristotelian claim is that, further developed, it will retain virtue morality's immersed attention to actual human experiences, while gaining the ability to criticize local and traditional moralities in the name of a more inclusive account of the circumstances of human life, and of the needs for human functioning that these circumstances call forth." (italics mine)
} 
In my view, virtue ethics points beyond itself to a different form of rationality. At the heart of this rationality is the universal requirement to justify our actions towards those who are affected by them (ourselves included). This rationality is firmly rooted not in the individual or communal striving for happiness, but in the autonomous will and its rational interest in freedom which all human beings have in common. ${ }^{49}$ The autonomous will is the source of unconditional deontological requirements which are laws of freedom urging us to respect basic human rights and to fulfill certain duties (the most basic duty being that we treat humanity in us and in other persons as an end in itself), thereby placing certain restrictions on the individual and collective pursuit of human flourishing.

Hilary Putnam suggested that we should clearly distinguish between 'universal ethics' and a 'universal way of life'. The resistance against ethical standards which are meant to be universal is rooted in the conviction that the right ethical principles must be substantiated in the form of an ideal society or an ideal way of life. If this were true, then the idea of universal norms and values would necessarily lead to dogmatism, authoritarianism and cultural hegemony. But, surely, there is something between this potentially dangerous idea of moral objectivity (moral objectivity meaning 'there is only one ideal way of living') and moral relativism which, I think, is no less dangerous.

As it is reasonable to think that the appreciation of cultural diversity should be a universal ethical value, it is also reasonable to assume that it is possible to discuss ethical problems without assuming the values of a particular tradition. For if this wasn't possible, it couldn't be assumed that there are existential problems in human life which are of universal significance. But this is what every sane person in every culture believes deep down: that there are universal human problems that transcend the cultural boundaries. So the Zen Buddhist, for example, believes that one way of life leads to satori (understanding) and the other leads to pain. And when he says so he is making a universalist claim. ${ }^{50}$ There are different value concepts in different cultural traditions which shouldn't be reduced to thin ethical concepts. So far, so good! But there is also in every culture the human potential for transcending one's one culture. The whole idea of a culture which has only thick ethical concepts is - as we have stated already - probably a myth. ${ }^{51}$

\footnotetext{
${ }^{49}$ I think Nussbaum is right when she says that "the ancient Greeks (before and including Aristotle) had no concept exactly corresponding to the Christian concept of the 'will"” (Nussbaum 1989 ...).

${ }^{50}$ Putnam, Hilary (1994): "Pragmatism and Relativism: Universal Values and Traditional Ways of Life", in: Hilary Putnam, Words and Life, Cambridge/MA: Harvard University Press 1994, p. 182-197, p. $190 \mathrm{f}$.

${ }^{51}$ Cf. Putnam 1994, p. 191.
} 
Let me quote Isaiah Berlin to make this clear:

"Communities may resemble each other in many respects, but the Greeks differ from Lutheran Germans, the Chinese differ from both; what they strive after, and what they fear or worship is scarcely ever similar. This view has been called cultural or moral relativism (...) It is not relativism. Members of one culture can, by the force of imaginative insight, understand (...) the values, the ideals, the forms of life of another culture or society, even those remote in time or space. They may find those values unacceptable, but if they open their minds sufficiently they can grasp how one might be a full human being, with whom one could communicate, and at the same time live in the light of values different from one's own, but which nevertheless one can see to be values, ends of life, by the realization of which men could be fulfilled."

To be able to enter imaginatively into another culture, its values and ideals, is indeed essential when it comes to intercultural ethical thinking. And since I am convinced that this is a potential which all human beings share I am confident that it is possible to reach a certain amount of agreement on both common norms and common values. ${ }^{53}$ Many of the ideas which are captured in human rights (rights and freedoms to which all humans are entitled) are rooted in a universal way of human thinking, namely in a form of reflection which exists in different cultural traditions, but transcends them: asking what is characteristic of human beings generally. This way of thinking leads mainly to norms, that is to say: to restrictions to what we are allowed to do. In addition to them, however, we also need if not universal then crosscultural values like the appreciation of culture diversity in the intercultural field. For "[w]ithout our human manifold of values, there is no vocabulary for norms (...) to be stated in. " ${ }^{54}$ An ethical approach which is exclusively based on restrictions is bound to fail.

The German philosopher Jürgen Habermas once said to the American philosopher Hilary Putnam in a private conversation: "We need some categorical imperatives, but not too many." 55 I totally agree with that. We need them, but too many of them would lead to dogmatism and authoritarianism. And in my opinion the essentially formal and abstract character of these norms is an advantage and not - as many have claimed - a disadvantage. For abstract universal norms are to a certain degree (there are limits to this!) open to culturally

\footnotetext{
${ }^{52}$ Berlin, Isaiah (1988): “On the Pursuit of the Ideal”, in: The New York Review of Books 17 (1988), p. 11-17, Berlin 1988, p. 15, italics mine.

53 Unterschied erklären!

${ }^{54}$ Putnam 2002, p. 119.

${ }^{55}$ Putnam, Hilary (2002): The Collapse of the Fact-Value-Dichotomy, Cambridge/MA: Harvard University Press 2002, p. 114.
} 
diverse implementations. They are not the product of contingent social worlds which vary as the different 'life worlds' vary; they are at home (so to speak) on the 'metalevel' constituted by rational reflection. ${ }^{56}$

Let me conclude with another remark of Hilary Putnam's and a subsequent thesis of mine. Putnam wrote:

"I have often remarked to friends that in ethics we need both Aristotelian and Kantian insights, and I never cease to be astonished at the resistance I meet when I say this. Again and again I am told that it is 'very hard' (in a tone of voice that implies: 'impossible') to reconcile a concern with human flourishing with Kantian ethics."

I believe that in a sense both Putnam and his skeptical friends are right. It is, indeed, difficult to reconcile these two forms of rationality, but surely they must be reconcilable and indeed complementary since they represent two indispensable sides of our practical rationality.

\footnotetext{
${ }^{56}$ Cf. Putnam 2002, p. 112.
}

${ }^{57}$ Putnam 2002, p. 134. 